\title{
La caridad en la historia del cristianismo: algunas manifestaciones en la Andalucía bajomedieval
}

Juan Carlos Arboleda Goldaracena

\section{(2) OpenEdition}

\section{Journals}

\section{Edición electrónica}

URL: http://journals.openedition.org/medievalista/356

DOI: 10.4000/medievalista.356

ISSN: 1646-740X

\section{Editor}

Instituto de Estudos Medievais - FCSH-UNL

\section{Referencia electrónica}

Juan Carlos Arboleda Goldaracena, «La caridad en la historia del cristianismo: algunas manifestaciones en la Andalucía bajomedieval », Medievalista [En línea], 14 | 2013, Puesto en línea el 01 julio 2013, consultado el 01 mayo 2019. URL : http://journals.openedition.org/medievalista/356 ; DOI : 10.4000/medievalista.356 
Título: La caridad en la historia del cristianismo: algunas manifestaciones en la Andalucía bajomedieval

Autor(es): Juan Carlos Arboleda Goldaracena

Enquadramento Institucional: Universidad Pablo de Olavide, Sevilla, España

Contacto: jcarbgol@upo.es

Fonte: Medievalista [Em linha]. №14, (Julho - Dezembro 2013). Dir. José Mattoso.

Lisboa: IEM.

Disponível em: http://www2.fcsh.unl.pt/iem/medievalista/

ISSN: 1646-740X

\section{Resumo}

La historia del cristianismo católico a menudo olvida que la base de esta religión es el ejercicio de la caridad hacia el prójimo por encima de todas las cosas. En este trabajo pretendemos ilustrar cómo vivían este mandato los cristianos andaluces de finales de la Edad Media, precisamente a través de un grupo de asociaciones laicales muy abundantes en esta región: las hermandades y cofradías. Las cofradías andaluzas bajomedievales fueron instituciones formadas mayoritariamente por laicos que llevaron a cabo una intensa actividad benéfico-social para con los habitantes de los núcleos urbanos donde residían. Ya fueran cofrades o no, aquellas personas que gozaban de una buena situación socioeconómica acudieron a las cofradías para que, sobre todo, les asistieran en el paso al más allá. Esta asistencia se manifestaba en los momentos previos a la muerte, pero también en todo tipo de honras fúnebres por las almas de los difuntos. No obstante, no era esta la única actividad benéfica desarrollada por estas instituciones, sino que también se ocuparon de ejercer la caridad en otras múltiples facetas que se estudian en el presente trabajo.

Palavras-chave: cristianismo, Andalucía, cofradías, asistencia social, caridad. 


\section{Abstract}

In this paper we aim to analise one aspect which normally goes unnoticed when studying the history of Christianism: charity. During the end of the Middle Ages, Andalusian fraternities were institutions which carried out an intense activity for social welfare amongst the inhabitants of the places where they resided. Members of fraternities or not, those who enjoyed a comfortable socioeconomic position turned to them in order to be helped in the transit to the eternal glory, as they wanted. They asked for assistance in the wake before leaving the wordly life, in funeral processions, and in funeral services to shorten the time for purging sins. But fraternities also shared this solidarity with poor people. This assistance also included other kinds of activities which met the interests and needs of people of the age.

Keywords: Christianity, Andalusia, fraternities, social welfare, charity.

\section{La caridad en la historia del cristianismo: algunas manifestaciones en la Andalucía bajomedieval}

Juan Carlos Arboleda Goldaracena

\section{INTRODUCCIÓN}

No hay más que elegir uno cualquiera entre los montones de volúmenes dedicados a la historia del cristianismo romano y de la Iglesia católica ${ }^{1}$ para comprobar que esta historia está llena de personajes importantes, batallas, narraciones de concilios ecuménicos y pormenores sobre el esplendor artístico y mundano de una institución

\footnotetext{
${ }^{1}$ Nos referiremos en la totalidad de este trabajo a esta rama del cristianismo.
}

Medievalista online $N^{0} 14 \mid$ Julho - Dezembro 2013 @ IEM - Instituto de Estudos Medievais 2 www2.fcsh.unl.pt/iem/medievalista 
cuyos orígenes estuvieron muy alejados del lujo y la ostentación por los que se ha caracterizado en los siglos posteriores. Pero no hay nada en esas historias que refleje lo que sin duda es -0 al menos debería ser- la seña de identidad más pura de los cristianos: la caridad. Ya desde sus orígenes, la comunidad de seguidores de Jesús se caracterizó por el que indudablemente es el mandamiento que resume las enseñanzas del nazareno: "Un mandamiento nuevo os doy: que os améis los unos a los otros, como yo os he amado" (Jn 13, 34) ${ }^{2}$.

Esta tendencia al inmovilismo y al estudio de la evolución histórica de la Iglesia desde una perspectiva que mira únicamente a la jerarquía eclesiástica parece haberse roto en las últimas décadas, para dejar paso a nuevas líneas de investigación centradas en el laicado y en una aproximación más evangélica a la historia del cristianismo. En este sentido, ha adquirido mucha importancia la reflexión en torno a los laicos ${ }^{3}$ como eje central de la vida de la Iglesia, pues son estos los que en definitiva asumen y viven las decisiones de una jerarquía en ocasiones demasiado alejada de la realidad social en las diferentes épocas históricas. Por otra parte, se ha publicado recientemente en España una Historia de la Iglesia que apunta directamente a la caridad como eje vertebrador de la evolución del cristianismo ${ }^{4}$. El trabajo que presentamos es deudor sin duda de ella, pues esta obra es la que establece las líneas maestras que seguimos en la presente investigación.

Antes de comenzar, creemos necesarias una serie de aclaraciones. En primer lugar, no podemos olvidar que la investigación en historia de las religiones no deja de ser un ámbito controvertido y bañado por la polémica en numerosas ocasiones, en cuanto se pone siempre bajo sospecha al investigador, alegando que un campo tan trascendental para el desarrollo humano puede contaminar el estudio y limitar la objetividad del historiador. Véanse a este respecto las reflexiones del Dr. Francisco Díez de Velasco ${ }^{5}$,

\footnotetext{
${ }^{2}$ Para una reflexión más profunda en torno a esta idea, véase: LABOA GALLEGO, Juan $\mathrm{M}^{\mathrm{a}}$ - Por sus frutos los conoceréis. Historia de la caridad en la Iglesia. Madrid: San Pablo, 2011. ISBN: 978-84-2853887-9, pp. 5-10.

${ }^{3}$ Una obra fundamental para abordar este tema es: LABOA GALLEGO, Juan $\mathrm{M}^{\mathrm{a}}$ - Los laicos en la Iglesia. Madrid: BAC, 2003. ISBN: 84-7914-662-1.

${ }^{4}$ LABOA GALLEGO, Juan $\mathrm{M}^{\mathrm{a}}$ - Por sus frutos los conoceréis..., ob. cit.

${ }^{5}$ DÍEZ DE VELASCO, Francisco - Teorías y metodologías para el estudio de las religiones. Recurso online. Disponible en: <http://webpages.ull.es/users/fradive/masterupo/index.html> [Última consulta: 19/2/2012]
} 
en las que defiende la necesidad de una diferenciación clara entre las distintas ramas de la investigación en torno a las religiones, utilizando para ello un criterio fundamental: la confesionalidad o aconfesionalidad del investigador. Es decir, un historiador de las religiones ha de diferenciarse claramente de un teólogo en el hecho de que el primero no busca enseñar a creer ni transmitir creencias, sino mostrar y tratar de explicar por qué en las diferentes etapas históricas las diversas religiones se han manifestado como parte esencial de la existencia del ser humano.

Nuestra opinión, en la línea del profesor Díez de Velasco, se basa en la necesidad imperante de la objetividad a la hora de abordar el estudio histórico, siempre teniendo en cuenta que la labor historiográfica, por mucho que se intente, nunca podrá estar depurada de cierto matiz de subjetividad, porque eso es algo inherente al propio ser humano. Pero también pensamos que, como historiadores de la religión cristiana, y, más en concreto, de la Iglesia católica, la objetividad se garantiza -independientemente de las creencias que cada uno pudiera tener- en el hecho de estudiar la Iglesia como una sociedad terrena más. Así lo apunta el Dr. Sánchez Herrero ${ }^{6}$, destacando que la Iglesia no es más que la comunidad de hombres y mujeres que creen en Jesucristo - no es tarea del historiador explicar esa creencia-, y en su carácter de comunidad humana es posible estudiarla como un grupo más de personas de cualquier sociedad y época. Cada uno de los acontecimientos de su devenir histórico pueden explicarse racionalmente, pero siempre teniendo en cuenta dos problemas fundamentales a los que debemos enfrentarnos: la tentación de interpretar los documentos desde el presente, y no en su contexto; y la necesidad de un verdadero análisis crítico que nos permita formular a las fuentes las preguntas adecuadas.

El trabajo que presentamos es un enfoque distinto de la historia de la Iglesia desde el punto de vista de la caridad. El amor fraterno ha estado presente en todos los momentos de la vida del cristianismo, aunque muchas veces haya quedado oculto o eclipsado por funestos acontecimientos que poco tenían que ver con el mensaje evangélico. Queremos ofrecer una visión de cómo se vivía este mandamiento del amor expresado por Jesús en un lugar y un tiempo concretos: Andalucía en la Baja Edad Media. Para ello,

${ }^{6}$ SÁNCHEZ HERRERO, José - "Apuntes para un manual de Historia de la Iglesia medieval, siglos V al XV". En: Historia, Instituciones, Documentos. No 31, (2004), pp. 645-658. ISSN: 0210-7716.

Medievalista online $\mathrm{N}^{0} 14 \mid$ Julho - Dezembro $2013 \odot$ IEM - Instituto de Estudos Medievais 4 www2.fcsh.unl.pt/iem/medievalista 
recurriremos al estudio de las instituciones eclesiásticas más puramente laicales (aunque sin descartar la presencia de clérigos en ellas) que podemos encontrar en el seno de la Iglesia católica: las hermandades y cofradías, agrupaciones de laicos que se unen para dar culto a la divinidad (Dios, María, los santos) y conseguir diversos fines (ejercer la caridad, ayudarse mutuamente, realizar penitencia... $)^{7}$. Nacen en la Plena Edad Media y van configurándose en torno a diversas tipologías, entre las cuales destacarán por su importancia las cofradías de Semana Santa o Pasión, que no surgirán sino hasta finales del siglo XV y, sobre todo, durante las primeras décadas del XVI.

Para el período estudiado por nosotros, en la biliografía que acabamos de referir queda resumido perfectamente el estado de la cuestión en cuanto al conocimiento actual de estas instituciones: en líneas generales, y para el caso andaluz de la Baja Edad Media y comienzos de la modernidad, conocemos su surgimiento, su funcionamiento interno y externo y las actividades que llevaban a cabo estas corporaciones. No obstante, el tema de la actividad benéfica no ha recibido hasta el momento la dedicación de muchos estudios, algo que justifica precisamente la elección del tema para este trabajo ${ }^{8}$.

\footnotetext{
${ }^{7}$ Para el estudio de su surgimiento y evolución en Andalucía, es necesario acudir a las obras del profesor José Sánchez Herrero. Entre las muchas que ha escrito, solo o en colaboración con otros autores, destacamos algunas: SÁNCHEZ HERRERO, José - La Semana Santa de Sevilla. Madrid: Sílex, 2003. ISBN: 978-84-7737-120-5; "El origen de las cofradías de Semana Santa o de Pasión en la Península Ibérica". En: Temas Medievales. Buenos Aires. No 6, (1996), pp. 31-79. ISSN: 0327-5094; "El origen de las cofradías penitenciales". En: VV.AA. (Eds.) - Sevilla Penitente. Sevilla: Gever, 1995, tomo I, pp. 1355. ISBN: 84-88566-32-8; "Las cofradías de Semana Santa de Sevilla durante la modernidad. Siglos XV a XVII". En: SÁNCHEZ MANTERO, Rafael et al. (eds.) - Las cofradías de Sevilla en la modernidad. Sevilla: Universidad, 1988, pp. 27-88. ISBN: 84-472-0509-6; "Las cofradías sevillanas. Los comienzos". En: SÁNCHEZ HERRERO, José et al. (eds.) - Las cofradías de Sevilla: historia, antropología, arte. Sevilla: Universidad, 1985, pp. 9-34. ISBN: 84-472-0511-8; "La evolución de las hermandades y cofradías desde sus momentos fundacionales hasta nuestros días". En: Consejo General de Hermandades y Cofradías de la Ciudad de Sevilla. Recurso online. Disponible en: <http://www.hermandades-desevilla.org/hermandades/historiahermandades.htm> [Última consulta: 19/2/2012]; "Piedad y artes plásticas. La devoción a la Preciosa Sangre de Cristo durante los siglos XIII a los primeros años del XVI y su influencia en las manifestaciones artísticas". En: Actas do Colóquio Internacional: Piedade popular. Sociabilidades-Representações-Espiritualidades. Lisboa: Terramar, 1999, pp. 411-432. ISBN: 972-710253-0; SÁNCHEZ HERRERO, José y PÉREZ GONZÁLEZ, Silvia M M $^{\mathrm{a}}$ - "La Cofradía de la Preciosa Sangre de Cristo de Sevilla. La importancia de la devoción a la Preciosa Sangre de Cristo en el desarrollo de la devoción y la imaginería de la Semana Santa". En: Aragón en la Edad Media. Homenaje a la profesora Carmen Orcástegui Gros. Zaragoza. No XIV-XV, (1999), pp. 1429-1452. ISSN: 0213-2486. Las conclusiones del Dr. Sánchez Herrero, aun cuando en ocasiones se refieren al caso de Sevilla, pueden aplicarse al resto de lugares de la Península, como él mismo refiere.

${ }^{8}$ Un antecedente directo de nuestro estudio es el de la Dra. Silvia María Pérez González: PÉREZ GONZÁLEZ, Silvia María - "Aspectos socio-caritativos de las Cofradías de la Cruz andaluzas (siglos XV y XVI)". En: Actas del IV Congreso Internacional de Hermandades y Cofradías de la Vera Cruz, Zamora, 2008, pp. 717-738. ISBN: 84-96100-38-3.
}

Medievalista online № 14| Julho - Dezembro 2013 @ IEM - Instituto de Estudos Medievais 5 www2.fcsh.unl.pt/iem/medievalista 
La elección de un marco geográfico concreto viene impuesta por varias razones: en primer lugar, la riqueza de la documentación disponible en cuanto a la tipología y temática trabajadas. Como indicaremos más adelante, la base documental de nuestro trabajo se ha centrado en un corpus de reglas de hermandades y cofradías andaluzas de los siglos XIV a XVI, que fue recopilado hace ya algunos años por los miembros del grupo de investigación al que pertenecemos ${ }^{9}$. Por otra parte, la representatividad de la región andaluza, a pesar de su heterogeneidad geográfica y cultural a finales de la Edad Media, radica en el hecho de que los territorios que a partir del siglo XIII fueron incorporándose a los dominios cristianos adoptaron enseguida el patrón religioso imperante a finales de la Edad Media: la religiosidad cristiana andaluza de los siglos XIV a XVI no es otra que la religiosidad castellana traída a estas tierras por los conquistadores ya durante el siglo XIII, que bebe sin duda de las fuentes de la Europa cristiana medieval.

¿Son representativas las hermandades y cofradías andaluzas para ilustrar lo que sucedía en el resto de la Península? Creemos que, por lo dicho anteriormente, sí. Y es más, podemos acudir a estudios de otros autores que se centran en otros ámbitos geográficos para constatar que lo expuesto por ellos coincide plenamente con lo apreciado por autores como Sánchez Herrero ${ }^{10}$ en sus trabajos dedicados a las cofradías andaluzas bajomedievales $^{11}$. El objetivo de nuestro estudio, por razones que atañen entre otras cosas a la limitación espacial, no nos permite centrarnos en establecer comparativas con otras regiones, si bien es algo que pretendemos llevar a cabo en trabajos futuros. No obstante, y en cuanto a referencias bibliográficas que puedan ayudar a clarificar este aspecto, recomendamos la consulta de la llamada Confraternities Collection, una

\footnotetext{
9 "HUM686-Centros de estudio e investigación de la religiosidad andaluza", adscrito primeramente a la Universidad de Sevilla y actualmente al Área de Historia Medieval de la Universidad Pablo de Olavide. ${ }^{10}$ Ver nota 7.

${ }^{11}$ A modo de ejemplo, y aunque la temática de su trabajo se centre en la mujer, la Dra. Ángela Muñoz Fernández describe un panorama general de lo que eran las cofradías castellanas durante los siglos XV y XVI: MUÑOZ FERNÁNDEZ, Ángela - "Las mujeres en los ámbitos institucionales de la religiosidad laica: las cofradías devocionales castellanas". En: MUÑOZ FERNÁNDEZ, Ángela y GRAÑA CID, Mª del Mar - Religiosidad femenina: expectativas y realidades (ss. VIII-XVIII). Madrid: Al-Mudayna, 1991, pp. 93-114. ISBN: 84-87090-05-2.
} 
recopilación bibliográfica internacional elaborada por la sociedad canadiense Confraternitas: The society for Confraternities Studies ${ }^{12}$.

\section{METODOLOGÍA DE TRABAJO}

Nuestro trabajo, como ya hemos apuntado, se asienta documentalmente en las reglas de las propias hermandades y cofradías. Las reglas constituyen el conjunto de normas y cánones que rigen la vida interna y las actividades públicas de estas corporaciones: sus fines y objetivos religiosos, el culto y su residencia, el gobierno y sus oficiales, la gestión y el control del patrimonio, la caridad, la estación de penitencia, etc. ${ }^{13}$. No podemos olvidar que este tipo de documentos son una parte importante del Patrimonio Histórico y una fuente muy valiosa de la que se nutren la Historia y el Patrimonio Documental $^{14}$. Nosotros hemos trabajado con un total de trece reglas ${ }^{15}$ de cofradías andaluzas bajomedievales, enmarcadas en un arco cronológico comprendido entre los años de 1336 (fecha de la primera regla) y 1520 (fecha de la última). Aunque nuestro estudio se introduzca en el primer cuarto del siglo XVI, podemos afirmar que no hay una ruptura en la vida y características de las cofradías, que seguirán siendo medievales hasta la llegada de las doctrinas propugnadas por el Concilio de Trento ${ }^{16}$. Las reglas consultadas pertenecen a hermandades y cofradías radicadas en localidades de cinco diócesis andaluzas: Sevilla (Sevilla ${ }^{17}$, Alcalá del Río ${ }^{18}$, Carmona $^{19}$, Écija $^{20}$, Salteras $^{21}$ ),

12 The Confraternities Collection. Recurso en línea. Disponible en: <http://www.crrs.ca/Confraternitas/collect.htm> [Última consulta: 20/3/2013].

${ }^{13}$ Para una mayor profundización en la conservación de este tipo de documentación, puede consultarse la siguiente obra: LÓPEZ GUTIÉRREZ, Antonio J. y RODRÍGUEZ MATEOS, Joaquín - Los archivos de las hermandades religiosas. Manual de organización de fondos. Sevilla: G.E.A., 1993. ISBN 84-6045659-5.

${ }^{14}$ IDEM - Archivos y documentos en las hermandades sevillanas. Sevilla: Castillejo, 2000, p.16. ISBN: 84-8058-137-9.

${ }^{15}$ Todas pueden encontrarse en: SÁNCHEZ HERRERO, José (Dir.) y PÉREZ GONZÁLEZ, Silvia M ${ }^{\mathrm{a}}$ (Coord.) - CXIX Reglas de Hermandades y Cofradías andaluzas. Siglos XIV, XV y XVI. Huelva: Universidad de Huelva, 2002. ISBN: 84-95699-34-6.

${ }^{16}$ ARBOLEDA GOLDARACENA, Juan Carlos - "Contrarreforma y religiosidad popular en Andalucía: cofradías y devoción mariana". En: Tiempos modernos: revista electrónica de Historia Moderna, vol. 7 , n²0, (2010). ISSN: 1699-7778.

17 "I. Hermandad y Hospital de Peregrinos de Nuestra Señora del Pilar (Sevilla, 1336)". Hermandad benefactora.

"II. Hermandad del Hospital del Salvador o de la Misericordia (Sevilla, 1349, 1390)". Hermandad benefactora.

Medievalista online $\mathrm{N}^{0} 14 \mid$ Julho - Dezembro 2013 @ IEM - Instituto de Estudos Medievais 7 www2.fcsh.unl.pt/iem/medievalista 
Huelva $\left(\mathrm{Niebla}^{22}\right)$, Córdoba (Córdoba ${ }^{23}$, Palma del Río $\left.{ }^{24}\right)$, Jaén (Jaén ${ }^{25}$ ) y Málaga $\left(\right.$ Ronda $\left.^{26}\right)$. Dada su publicación en formato electrónico, y para facilitar el sistema de citas bibliográficas, de aquí en adelante haremos alusión a ellas mencionando únicamente el número de regla que les corresponde en el conjunto de la obra (en cifras romanas) y el capítulo en concreto que se les ha asignado dentro de la misma (en caracteres arábigos).

También hemos de hacer referencia al hecho de la diversidad de tipologías dentro de las congregaciones objeto de nuestro estudio. ¿Cuántos tipos de cofradías existen? Siguiendo a los Dres. Sánchez Herrero y Pérez González ${ }^{27}$, podríamos distinguir entre cofradías devocionales, cofradías benefactoras, cofradías profesionales, cofradías de clérigos, cofradías agrupación de personas pertenecientes a un mismo grupo social, o cofradías agrupación de disminuidos físicos. Esta clasificación serviría para los últimos siglos medievales, cuando aún el fenómeno de la penitencia no ha llegado a estas corporaciones. A partir de este momento (finales del siglo XV y sobre todo inicios del XVI), podríamos distinguir entre las cofradías penitenciales propiamente dichas, también denominadas de Semana Santa o Pasión, cuyo fin principal para el que son fundadas es la penitencia pública, rindiendo culto a un pasaje concreto de la Pasión de Cristo; y las cofradías de disciplina, que sin venerar necesariamente algún momento pasionista, incorporaban la disciplina como elemento complementario de otros fines y

"III. Hermandad y Cofradía de San Pedro Apóstol y Mártir o de los correeros o guarnicioneros (Sevilla, hacia 1450)". Cofradía profesional.

"IV. Hermandad de la Santa Casa de la Misericordia (Sevilla, 1476, 1518)". Hermandad benefactora.

18 "XXXVII. Hermandad de la Misericordia (Alcalá del Río, 1515)". Hermandad benefactora.

19 "XLI. Hermandad y Cofradía de San Blas (Carmona, 1353)". Hermandad devocional.

20 "LII. Hermandad y Cofradía de la Santa Vera Cruz (Écija, 1519-1520)". Cofradía de Semana Santa o Pasión.

21 "LXXXII. Hermandad y Cofradía de la Santísima Trinidad (Salteras, 1438)". Hermandad devocional.

22 "CVIII. Hermandad y Cofradía de la Santa Caridad y Misericordia (Niebla, 1495, 1519)". Hermandad benefactora.

23 "LXXXV. Universidad de clérigos beneficiados parroquiales de Córdoba y Cofradía unida a dicha Universidad, compuesta de clérigos y laicos, hombres y mujeres (Siglos XIV-XV)". Cofradía de clérigos.

24 "XCV. Cofradía de Santa María (Palma del Río, Córdoba, Siglo XIV)". Cofradía devocional.

25 "CIX. Cofradía de Santa María Magdalena (Jaén, 1514)". Cofradía devocional.

26 "CXVII. Cofradía de la Santa Caridad y Misericordia de Nuestro Señor Jesucristo (Ronda, 1500)". Cofradía benefactora.

${ }^{27}$ SÁNCHEZ HERRERO, José - Las diócesis del reino de León. Siglos XIV y XV. León: Centro de Estudios e Investigación "San Isidoro", 1978, pp. 382-392. ISBN: 84-00-03796-0. PÉREZ GONZÁLEZ, Silvia $\mathrm{M}^{\mathrm{a}}$ - Los laicos en la Sevilla bajomedieval: sus devociones y cofradías. Huelva: Universidad, 2005, pp. 123-132. ISBN: 84-96373-61-4. 
devociones para los que son erigidas ${ }^{28}$. Al mencionar anteriormente en notas a pie de página a todas las institucioens, ya hicimos referencia a la tipología de cada una.

Una vez aclarados todos los términos, procedamos al estudio de las hermandades y cofradías andaluzas bajomedievales desde la óptica anunciada: la presencia en ellas del mandato evangélico de la caridad. Para ello, nos detendremos en analizar todas las actuaciones y mecanismos mediante los cuales los cofrades ponían de manifiesto en su vida diaria la importancia del mensaje de Jesús, ayudando a sus hermanos y viviendo en el seno de una verdadera comunidad en la que el eje vertebrador era la ayuda mutua, a través de las distintas formas mediante las cuales se manifestaba la caridad.

\section{LAS FORMAS DE LA CARIDAD}

Hemos desgranado nuestro estudio en diferentes apartados que reflejan de manera clara las distintas formas en que se manifestaba la actividad benéfico-asistencial de las hermandades y cofradías andaluzas en el período de su surgimiento. Pero creemos que previamente es necesario abordar dos aspectos importantes. En primer lugar, hemos de precisar el fundamento teológico de las cofradías para llevar a cabo su labor caritativa. Ya hemos especificado que este no es otro que el mandamiento evangélico del amor fraterno, pero es interesante señalar cómo se recibe (teóricamente) por parte de las cofradías. Para ello, no hay más que acudir a las introducciones de las diferentes reglas, donde encontramos disposiciones como las que siguen:

Primeramente, ordenamos et estableçemos que nos amemos et nos onrremos en la nuestra vida mientras que en este mundo mesquino beuimos et después en la nuestra muerte quando dél partiéremos segund que aquí en esta dicha Regla será ordenado en los capítulos adelante contenidos. ${ }^{29}$

\footnotetext{
${ }^{28}$ SÁNCHEZ HERRERO, José - "La evolución de las hermandades...", ob. cit.

${ }^{29}$ III, 1 .
} 
Hermanos, Dios sea amado i después el próximo syn el qual amor ninguno puede ser saluo, ca éstos son los mandamientos prinçipalmente a nos dados. Por ende, lo primero que auemos de guardar para que en la Hermandad aprouechemos en que seamos de un ánimo, esto es, de vn querer e vn coraçón en Dios e el bien e prouecho e caridad nuestra sea común al próximo, distribuyendo a cada vno segund lo que ouiere. Esto se entiende, al que más lo ouiere menester, uiéndolo el hermano mayor o quien él mandare o aquél que para ello por él e por el cabildo fuere eligido, segund que los christianos hermanos en la primitiua Iglesia fazían, anteponiendo lo propio a lo común y lo común a lo propio, ca ésta es la uerdadera caridad que no quiere lo ques suyo más lo que es de Jesu Christo, es a saber, pro del próximo, el por que syn caridad ninguno puede ser saluo, ques amor de Dios e del próximo, porque caridad todas las cosas uence y todas las cosas sufre e todas las cosas sostiene, porque Dios es caridad e el que está en caridad es en Dios e Dios en él. ${ }^{30}$

Por otro lado, es necesario precisar las bases económicas sobre las que se sustentaba la actividad benéfica de las cofradías. A este respecto, hemos de señalar que la documentación utilizada en el presente trabajo no es muy ilustrativa en lo que al tema se refiere, pues aunque las reglas y estatutos establecen en ocasiones, y siempre desde un punto de vista teórico, algunos aspectos relacionados con la economía cofradiera, en cualquier caso la información suele ser escasa. No obstante, el problema puede ser abordado utilizando otro tipo de documentación muy valiosa, como son los protocolos notariales. Para el caso andaluz, hay dos estudios que tratan el tema de manera magistral empleando la documentación mencionada o completándola con las reglas de las cofradías $^{31}$.

\footnotetext{
${ }^{30}$ IV, 1. Tres textos casi idénticos se recogen en: XXXVII, 1; CVIII, 1; CXVII, 1.

${ }^{31}$ PÉREZ GONZÁLEZ, Silvia M ${ }^{\mathrm{a}}$ - Los laicos ..., ob.cit., p.151-168; IDEM: "Aspectos socio-caritativos de las Cofradías de la Cruz...”, ob.cit.
} 
Salvada esta distancia, ¿qué nos aporta la documentación por nosotros utilizada? Se aprecia claramente que la actividad asistencial tiene un sustento claro en las limosnas recibidas por las cofradías. Las reglas estipulan la obligación contraída por los hermanos de pedir limosna todos los domingos, fiestas y viernes (todos los del año o solamente los de Cuaresma) ${ }^{32}$, debiendo turnarse según el protocolo establecido y bajo pena de sanción económica si no cumplen dicha función que se les encomienda. A veces esta petición se realiza con una mesa en la propia iglesia donde la cofradía tiene su $\operatorname{sede}^{33}$. En otras ocasiones, se establece una limosna obligatoria para todos los cofrades con ocasión de determinadas fiestas, como la de San Lucas ${ }^{34}$, que se destina a fines benéficos.

Algunas cofradías encargan a una persona determinada la recepción de las limosnas y donaciones que se emplearán en la labor caritativa ${ }^{35}$, debiendo ocupar el puesto durante un año. Las limosnas suelen conservarse en un arca, que en algunas cofradías ${ }^{36}$ se guarda bajo llave, con cuatro copias: una para los hermanos mayores, otra para los diputados, otra para los alcaldes y otra para los escribanos ${ }^{37}$. Aunque por lo general no suele especificarse la distribución de las limosnas en función de las distintas actividades benéficas, en algunos casos sí encontramos una partida económica dividida en tres frentes: un tercio para casar huérfanas, otro para la asistencia a los pobres y otro para otras necesidades, entre las que se incluye el entierro de los difuntos ${ }^{38}$. Solamente en un caso hemos podido documentar la utilización de las rentas de unas huertas donadas a la cofradía en un testamento para la realización de obras benéficas ${ }^{39}$. Recordemos que este tipo de sustento material está presente en la documentación notarial, pero rara vez aparece en las reglas de las cofradías, precisamente por el carácter duradero de estas -al

\footnotetext{
${ }^{32}$ IV, 13; CVIII, 13.

${ }^{33}$ LII, 23.

${ }^{34} \mathrm{LXXXV}, 109$.

${ }^{35}$ XXXVII, 6; CXVII, 6.

${ }^{36}$ XXXVII, 7.

${ }^{37}$ Para un análisis más exhaustivo de los puestos de gobierno y control en el seno de las cofradías andaluzas bajomedievales, puede consultarse: ARBOLEDA GOLDARACENA, Juan Carlos - "El gobierno de las hermandades y cofradías andaluzas en la Baja Edad Media". En: VV.AA. (Eds.) Mundos medievales: espacios, sociedades y poder. Homenaje al Profesor José Ángel García de Cortázar. Santander: Universidad de Cantabria-Fundación Marcelino Botín-Instituto de Estudios Riojanos, 2012, vol. 2, pp. 1005-1014. ISBN: 978-84-8102-649-8.
}

${ }^{38}$ XXXVII, 7; CXVII, 7.

${ }^{39} \mathrm{IV}, 37$. 
menos, en principio- y la temporalidad de los bienes materiales o las propiedades concretas.

\subsection{La ayuda material a los propios cofrades en caso de necesidad}

Analizaremos en primer lugar la actividad benéfica dirigida a los propios integrantes de las cofradías. No olvidemos que, sobre todo en el período de surgimiento del movimiento cofrade, los miembros de las hermandades y cofradías veían a estas instituciones como una parte esencial que conformaba su identidad personal y grupal. Y esto es así porque, al ingresar en alguna de las múltiples corporaciones presentes en las ciudades andaluzas, los cofrades adquirían una serie de obligaciones que debían cumplir (siempre bajo pena de sanción económica), pero recibían también la garantía de determinados derechos y beneficios, muy importantes sobre todo en situaciones de necesidad en esta vida y en el paso al más allá. Por tanto, si por algo se caracterizaban las cofradías bajomedievales y pretridentinas, es por una ayuda constante a los necesitados, pero también a sus propios cofrades, que se sentían arropados de manera ejemplar dentro de su propia hermandad.

En esta ocasión, nos ocupamos de la ayuda material en caso de pobreza o necesidad. Un buen número de reglas recogen la obligatoriedad de ayudar al cofrade que ha caído en la pobreza, estudiando para ello el tipo de necesidad y la cantidad material que debe aportársele $^{40}$. Si el hermano era tan pobre que no podía abonar la cantidad correspondiente a la comida que con cierta periodicidad celebraban algunas cofradías, se le condonaba esta deuda ${ }^{41}$. Además, en determinados tipos de corporaciones con un carácter marcadamente militar, esta ayuda a los cofrades se reflejaba también en casos de necesidad como la pérdida del caballo, ante el cual se remediaba el mal mediante la compra de uno nuevo ${ }^{42}$. Volveremos sobre la ayuda a los propios cofrades en otra de las situaciones en la que nos detendremos con posterioridad: la asistencia ante la enfermedad y la muerte.

\footnotetext{
${ }^{40}$ IV, 6; XLI, 12; LXXXII, 7; CVIII, 6; CIX, 29.

${ }^{41}$ III, 12.

${ }^{42} \mathrm{I}, 3$.
} 


\subsection{La caridad material extracorporativa con los pobres y necesitados}

Pero esta ayuda material no se manifestaba únicamente con los propios hermanos de la cofradía, sino también, y de forma muy especial, con los pobres y necesitados de la localidad donde las corporaciones tenían su residencia. La pobreza era una realidad latente en los pueblos y ciudades de la Europa medieval y moderna ${ }^{43}$, que las cofradías se apresuraban en remediar:

Por esta razón fueron levantadas las Confradrías i las hermandades, más por los pobres que por los ricos. ${ }^{44}$

Por lo general, se solía encomendar esta misión a dos hermanos, los cuales se encargaban de averiguar las necesidades de los pobres (a veces también se incluía a los encarcelados) y remediarlas en función de cada caso $^{45}$, siempre contando con la autorización del resto de la junta de gobierno. En ocasiones es el propio prioste, una de las figuras principales del gobierno de la cofradía, el que se encarga de visitar a los pobres $^{46}$. Además de la ayuda monetaria, las cofradías se encargaban de alimentar a muchas personas que no disponían de medios para ello, sobre todo con ocasión de determinadas fiestas y celebraciones, como el día de la comida de la cofradía ${ }^{47}$, la víspera de Pascua florida ${ }^{48}$ o el día de San Lucas ${ }^{49}$.

\footnotetext{
${ }^{43}$ Para ampliar este aspecto (en el ámbito europeo en general y el andaluz en particular), recomendamos dos obras fundamentales: CARMONA GARCÍA, Juan Ignacio - El extenso mundo de la pobreza: la otra cara de la Sevilla imperial. Sevilla: Ayto. de Sevilla, 1993. ISBN 84-86810-30-2; GEMEREK, Bronislaw - "L'emarginato". En LE GOFF, Jacques (Ed.) - L'uomo medievale. Roma: Laterza, 1987, pp. 391-421. ISBN: 978-88-420-4197-9.

${ }^{44}$ LXXXII, 4.

${ }^{45}$ XXXVII, 3; CXVII, 3.

${ }^{46} \mathrm{XCV}, 9$.

${ }^{47}$ III, 12.

${ }^{48}$ IV, 37.

${ }^{49}$ LXXXV, 7.
} 


\subsection{El hospital de la cofradía}

Los hospitales regentados por hermandades y cofradías surgen por el deseo de los propios cofrades de contar con un organismo de asistencia social más específico. Estas instituciones no se dedicaban únicamente al cuidado de los enfermos, sino que también atendían y acogían a los grupos sociales más desfavorecidos: pobres, viudas, viajeros y personas sin recursos en general ${ }^{50}$. Para el estudio del funcionamiento interno del hospital, contamos especialmente con una de las reglas presentes en nuestra documentación $^{51}$, que es la que nos aporta más información.

El gobierno del hospital estaba encabezado por un provisor, elegido entre diez hermanos, y al cual acompañaba una junta de cinco consejeros: dos físicos, dos cirujanos y un boticario, que trabajaban en el hospital ${ }^{52}$. La asistencia a los necesitados era completamente gratuita, incluyendo a enfermos, pobres, religiosos, emparedadas y cualquier colectivo que lo necesitara ${ }^{53}$. Los médicos del hospital debían también visitar a los hermanos bienhechores y atenderlos en sus necesidades, sin cobrar por ello, salvo la limosna voluntaria que cada hermano quisiera darles; el boticario les daba también las medicinas al costo, al igual que hacía con el hospital ${ }^{54}$. Por último, se establecía que no podrían ser acogidos en el hospital enfermos incurables ni ciegos, sino solamente aquellos muy pobres que estaban impedidos para ir a pedir limosna o los que estaban a punto de fallecer ${ }^{55}$.

\footnotetext{
${ }^{50}$ Para un estudio más exhaustivo pueden consultarse las siguientes referencias: CARMONA GARCÍA, Juan Ignacio - El sistema de la hospitalidad pública en la Sevilla del Antiguo Régimen. Sevilla: Diputación Provincial, 1979. ISBN: 84-500-3472-8; IDEM: Las redes asistenciales en la Sevilla del Renacimiento. Sevilla: Universidad, 2009. ISBN: 978-84-472-1180-7; PÉREZ GONZÁLEZ, Silvia M ${ }^{\mathrm{a}}$ "Aspectos socio-caritativos...", ob. cit; IDEM - Los laicos..., ob.cit., pp. 180-190.

51 "II. Hermandad del Hospital del Salvador o de la Misericordia (Sevilla, 1349, 1390)".

${ }^{52} \mathrm{II}, 3$.

${ }^{53}$ II, 5

${ }^{54}$ II, 6

${ }^{55}$ II, 11 .
} 


\subsection{La asistencia ante la enfermedad y la muerte}

Entramos en el apartado con más presencia de menciones en la documentación estudiada: la asistencia ante la enfermedad en esta vida y en el paso al más allá. No en vano las cofradías han sido consideradas en muchas ocasiones como verdaderas mutualidades de entierro ${ }^{56}$. Nadie puede negar que la enfermedad suponía en la Edad Media -y sigue suponiendo hoy en día- un obstáculo difícil de salvar para cuantos necesitaban de una buena salud que les permitiera garantizar el sustento a su familia. Además, si la enfermedad agravaba y se hacía inevitable el paso a la otra vida, la asistencia espiritual era la mejor ayuda que las cofradías podían prestar a sus miembros y allegados. Veamos detenidamente todos los mecanismos de actuación. Nos centraremos en primer lugar en la asistencia a los propios cofrades.

Cuando un cofrade se encontraba enfermo, su cofradía se encargaba de velarlo durante las noches que durara la enfermedad (hasta su recuperación o su muerte) ${ }^{57}$. En ocasiones se especifica el número de hermanos que deben efectuar estas visitas al domicilio del enfermo: cuatro hermanos ${ }^{58}$, el prioste con otro u otros dos cofrades por turnos ${ }^{59}$, dos cofrades por turnos ${ }^{60}$, los mayordomos viejos de la cofradía ${ }^{61}$, dos clérigos ${ }^{62}$ (a veces, se aclara que han de llevar sus sobrepellices y cobrar un real por cada noche ${ }^{63}$ ) encargados de rezar diversos salmos por el enfermo. Algunas cofradías estipulan un pago de dos maravedís semanales a los cofrades enfermos que además son pobres ${ }^{64}$. En otras ocasiones, se establece que a partir del tercer día de enfermedad, se aplican por el cofrade los oficios celebrados en diversas iglesias ${ }^{65}$.

Pero si a pesar de los cuidados y oraciones, la muerte llama a la puerta de alguna persona, el protocolo de actuación de las cofradías estaba bien definido. En primer

\footnotetext{
${ }^{56}$ SÁNCHEZ DOMÍNGUEZ, Paloma - Mujeres y cofradías en Málaga. Málaga: Arguval, 2003, p. 31. ISBN: 84-95948-34-6.

${ }^{57}$ III, 63.

${ }^{58}$ XXXVII, 30.

${ }^{59}$ XLI, 7.

${ }^{60}$ LXXXII, 6.

${ }^{61}$ LII, 18.

${ }^{62}$ LXXXV, 29.

${ }^{63} \mathrm{IV}, 18$.

64 XLI, 12.

${ }^{65}$ LXXXV, 27.
} 
lugar, y de forma unánime en la práctica mayoría de las corporaciones, se establece la obligatoriedad de acompañar el cadáver del difunto desde su fallecimiento hasta su entierro, normalmente por turnos de hermanos ${ }^{66}$. Estos deben ir con candelas (a veces con cuatro ciriales ${ }^{67}$ ) y no deben marcharse hasta que los oficios por el difunto no hayan acabado. Suelen emplearse velas de cera y un paño de terciopelo negro que se coloca sobre la caja del difunto ${ }^{68}$. Otras veces, el paño (en este caso, de seda) solamente se presta previo pago de 100 maravedís $^{69}$. Para el velatorio del difunto, a veces se especifican datos más concretos acerca de los cofrades que deben acudir: diez cofrades toda la noche $\mathrm{e}^{70}$, dos cofrades cada cuatro horas ${ }^{71}$, cuatro cofrades $^{72}$, el hijo $\mathrm{o}$ apaniaguado de cada cofrade durante la noche, las mujeres si se trata de una cofrada o las hijas o mancebas de cofrades si la fallecida era también hija o manceba ${ }^{73}$. Un cirio debe arder toda la noche junto al difunto ${ }^{74}$, cobrándose en ocasiones una libra de cera de los bienes del fallecido para tal fin ${ }^{75}$. Tras el velatorio, los diputados sacan el cuerpo de la casa y, una vez en la calle, este es tomado por los demás hermanos ${ }^{76}$, que marchan en procesión con él hasta la iglesia, seguidos por una $\mathrm{cruz}^{77}$.

Si el cofrade fallece fuera de la ciudad, normalmente se sale a las puertas de la misma para recibirlo $^{78}$. A veces se pone como condición que la distancia máxima a la que esté el difunto sea de un día (contando la ida y la vuelta), y en tal caso se le va a buscar ${ }^{79}$. Si era intención del difunto ser enterrado fuera de la ciudad, se le acompaña hasta la puerta $^{80}$, salvo en el caso de algunas iglesias extramuros, hasta las que sí llega la comitiva: Santa Ana, San Agustín y la Trinidad en Sevilla ${ }^{81}$; o San Lorenzo y Santa

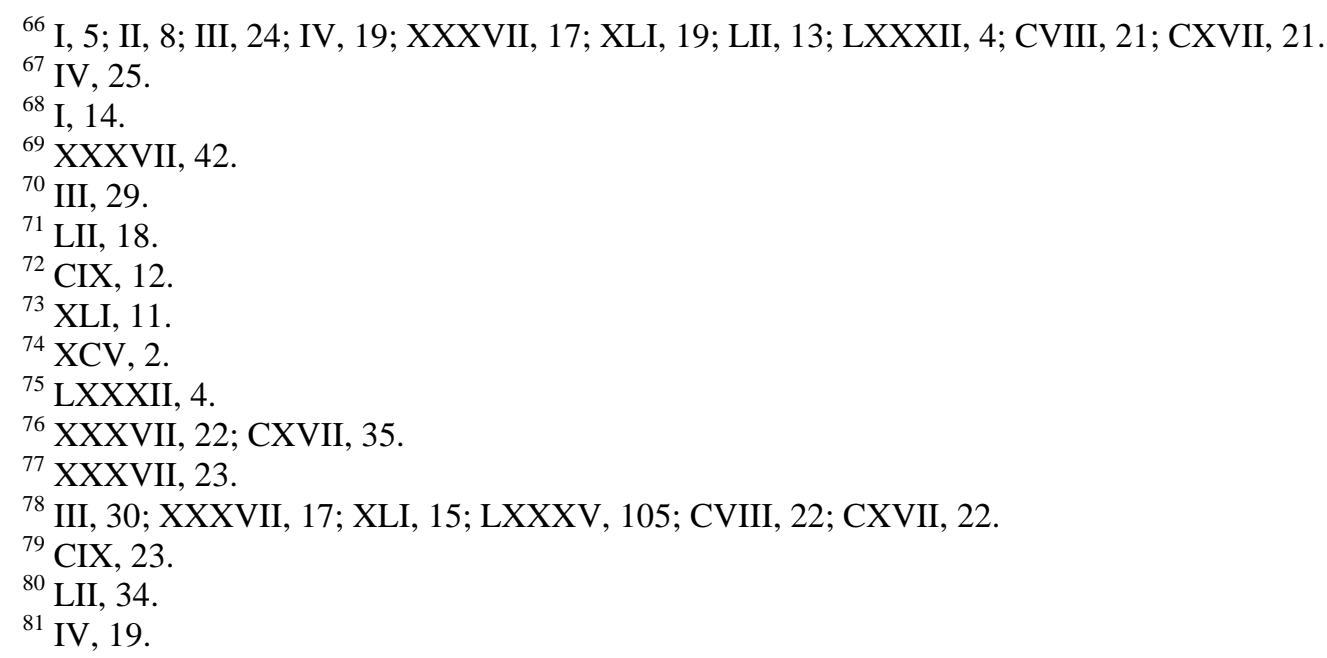


María del Pino en Niebla (Huelva) ${ }^{82}$. Si el cofrade fallecido residía en otra collación distinta a la de la cofradía, se le traía hasta la iglesia, o incluso se le acompañaba a otro templo dentro de la ciudad donde quisiera ser enterrado ${ }^{83}$. Las mozas eran veladas en la misma iglesia de la cofradía ${ }^{84}$, o en la de la collación donde residieran ${ }^{85}$, y a sus entierros solo debían acudir los diputados, por no fatigar a los hermanos. A veces, las viudas de la cofradía eran las que cosían la mortaja del difunto ${ }^{86}$, que se da gratuitamente al cofrade si es muy pobre ${ }^{87}$.

La mayoría de las cofradías establecen dos categorías de entierro: los de cabeza mayor (el cofrade y su mujer) y de cabeza menor (hijos y padres de cofrade que estén a su cargo). Por lo general, la participación de la mujer de los mismos beneficios que su marido queda justificada en la mayoría de las reglas aludiendo a que son parte de un mismo todo ${ }^{88}$. Otras veces, es necesario que, si la mujer enviuda, no se case de nuevo si quiere mantener sus privilegios dentro de la cofradía ${ }^{89}$. Hay cofradías que estipulan que en los entierros de cabeza menor ha de emplearse solamente la mitad de los cirios ${ }^{90}$ que en los de cabeza mayor (en los que se emplean doce cirios ${ }^{91}$ ). Otras veces se especifica que para dar la misma honra que a sus padres a los hijos de cofrade, estos han de ser mayores de diez años ${ }^{92}$. No obstante, también encontramos corporaciones en las que los hijos e hijas sin casar $^{93}$ y los padres y madres a cargo de los cofrades ${ }^{94}$ son enterrados con las mismas honras que si fueran miembros de la cofradía. A los parientes de hasta cuarto grado o paniaguados de cofrades, se les acompaña únicamente para sacar el cadáver de su casa, haciéndolo con treinta velas. Si quiere sesenta, ha de pagar cincuenta maravedís $^{95}$. A los criados y huéspedes de los cofrades, se les honra con

${ }^{82}$ CVIII, 22.

${ }^{83}$ XLI, 17, 20, 21.

${ }^{84}$ XXXVII, 24.

${ }^{85}$ CXVII, 36.

${ }^{86}$ LXXXII, 5.

${ }^{87}$ CIX, 28; XLI, 12.

${ }^{88}$ IV, 19; XXXVII, 17; CVIII, 21; CXVII, 21.

${ }^{89}$ II, 9.

${ }^{90}$ LII, 14.

${ }^{91}$ LII, 13.

${ }^{92}$ LXXXII, 16; LXXXII, 19.

${ }^{93}$ III, 25; IV, 19; XXXVII, 17; XLI, 11; CVIII, 24; CXVII; 24.

${ }^{94}$ III, 26; IV; 19; XXXVII, 17; CVIII, 24.

${ }^{95}$ III, 27. 
cuarenta candelas $^{96}$. Las personas que no pertenecen a la cofradía, pero se encomiendan a ella para que los asista en la hora de su muerte, deben pagar cierta cantidad económica: cien maravedís ${ }^{97}$, mil maravedís ${ }^{98}$, trescientos maravedís ${ }^{99}$. A veces la cantidad varía en función del entierro que elijan: cabeza mayor o cabeza menor; y si la persona en cuestión es pobre, se efectúa un entierro de cabeza menor ${ }^{100}$. Se prohíbe el entierro de esclavos, y si se descubre que los cofrades los hicieron pasar por sirvientes, deben pagar una multa de mil maravedís ${ }^{101}$.

Entre las oraciones y sufragios por el alma de los difuntos encontramos una gran variedad: rezar treinta veces el Padrenuestro ${ }^{102}$; rezar el Padrenuestro y el Ave María (cinco veces ${ }^{103}$, diez veces ${ }^{104}$, veinte veces ${ }^{105}$ ); celebrar dieciocho misas rezadas y dos cantadas por cada cofrade y su mujer ${ }^{106}$; o una cantada y cinco rezadas por los padres de los cofrades $^{107}$; vigilia y misa cantada por parte de cada clérigo miembro de la cofradía $^{108}$; una misa cantada y doce rezadas ${ }^{109}$; cuatro misas rezadas y una cantada por el alma de cada cofrade, debiendo pagarse setenta maravedís a los curas y diez al sacristán por cada ciclo de estas misas ${ }^{110}$; dos misas rezadas y una cantada ${ }^{111}$. A veces se especifica que la misa cantada ha de celebrarse un día y las rezadas al siguiente ${ }^{112}$.

En ocasiones, como en el caso de la Universidad de beneficiados de Córdoba, el carácter clerical del fallecido marcaba claramente una diferencia en cuanto al boato de las honras fúnebres. Si el clérigo en cuestión era beneficiado, se mandaba tocar las campanas, se celebraba un responso en su casa y posteriormente se llevaba el cadáver a

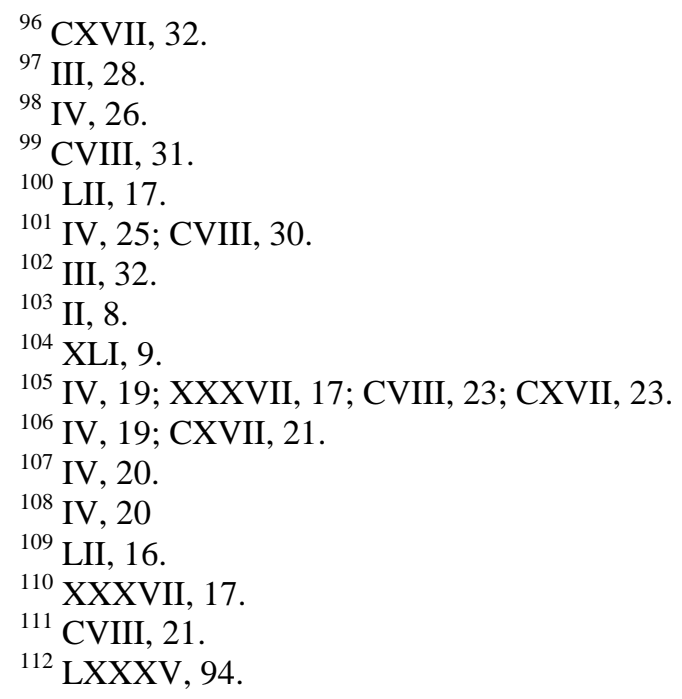


la iglesia ${ }^{113}$. Se nombraba a otros dos clérigos para que, sin sobrepelliz ${ }^{114}$, se encargaran de la organización de todos $\operatorname{los}$ oficios ${ }^{115}$ y oraciones varias en honor del difunto ${ }^{116}$. Se celebraba además una misa cantada y diversas misas rezadas ${ }^{117}$. A los nueve días y al año del fallecimiento, se celebraban las correspondientes memorias ${ }^{118}$. Además, se ordena que solamente se llevará en hombros el cadáver de los beneficiados ${ }^{119}$.

Si el clérigo era menesteroso ${ }^{120}$, o el fallecido era cofrade pero no clérigo ${ }^{121}$, se celebraba una vigilia y una misa cantada. Si se trataba de familiares de clérigos, estos habían de pagar cien maravedís para la celebración de la vigilia y la misa cantada ${ }^{122}$. Para el entierro de conversos ${ }^{123}$ o de otras personas no pertenecientes a la corporación, era necesario abonar el coste de los entierros y honras fúnebres, en función de la tipología de cada uno ${ }^{124}$.

Al finalizar las honras fúnebres, a veces se acudía a casa del difunto y se seguía rezando allí $^{125}$. Otras, se celebraba una comida a la que cada cofrade debía llevar algo para compartir con los demás ${ }^{126}$.

Todo lo que hemos enunciado se aplicaba en los casos de fallecimiento de algún cofrade y sus familiares, pero las cofradías se ocupaban también de la atención a los pobres en el paso a la otra vida. En muchas de ellas encontramos la figura de uno ${ }^{127}$ o dos ${ }^{128}$ hermanos encargados de estar al tanto de los pobres y abandonados que fallecían en la localidad, a los cuales la cofradía, con todos sus cofrades presentes, debía enterrar dignamente. Si estos fallecidos tenían algunos bienes, a veces se estipula el cobro de

\footnotetext{
${ }^{113}$ LXXXV, 30.

${ }^{114}$ LXXXV, 96.

${ }^{115} \mathrm{LXXXV}, 31$.

${ }^{116}$ LXXXV, 32.

${ }^{117} \mathrm{LXXXV}, 33$.

${ }^{118}$ LXXXV, 36.

${ }^{119}$ LXXXV, 70.

${ }^{120}$ LXXXV, 38.

${ }^{121}$ LXXXV, 39.

${ }^{122}$ LXXXV, 41.

${ }^{123}$ LXXXV, 101.

${ }^{124}$ LXXXV, 98, 99, 100.

${ }^{125}$ LXXXII, 5.

$126 \mathrm{XCV}, 5$.

${ }^{127}$ XXXVII, 4.

${ }^{128}$ CXVII, 4.
} 
dos libras de cera para hacer frente a los gastos derivados de las honras fúnebres ${ }^{129}$. Si se sabe que el fallecido o la fallecida estaban casados o tenían hijos, no se les entierra, salvo que sean muy pobres, caso en el que se les da un real para los gastos ${ }^{130}$. Si el pobre ha fallecido en casa de un amigo o conocido, se averigua si este tiene cofradía que lo entierre; si no, se le da algo de dinero ${ }^{131}$. Por último, si un hermano recibe en su casa a un pobre y este muere, se le entierra como cabeza menor con seis cirios, la mitad de la cera y una misa rezada ${ }^{132}$.

\subsection{Otras necesidades: doncellas, cautivos y presos}

Nos ocupamos ahora de otro tipo de actividades caritativas ejercidas por las cofradías en la Baja Edad Media. En muchas reglas se especifica que el dinero sobrante, después de haber atendido el resto de necesidades ya mencionadas, se destinaría a casar huérfanas ${ }^{133}$; o a casar huérfanas y redimir cautivos ${ }^{134}$.

La dotación de doncellas para el matrimonio constituyó una obra de caridad fundamental en algunas cofradías ${ }^{135}$, habida cuenta de que la consecución de una dote suponía una verdadera obsesión para muchas mujeres, que habían sido educadas desde pequeñas para tal fin ${ }^{136}$. El procedimiento era el siguiente: una vez que la candidata solicita la ayuda de la cofradía, se estudia el caso en cabildo y se investiga a la susodicha. Si se comprueba que no hay impedimentos y que cumple todos los requisitos

\footnotetext{
${ }^{129}$ XXXVII, 15; CXVII, 20.

${ }^{130}$ XXXVII, 6.

${ }^{131}$ XXXVII, 16; CVIII, 27.

${ }^{132}$ LII, 38.

${ }^{133}$ IV , 6; CVIII, 6.

${ }^{134}$ II, 12.

${ }^{135}$ SÁNCHEZ HERRERO, José - La Semana Santa..., ob.cit., pp. 152-158; IDEM - "La acción benéfica de las cofradías durante los siglos XIV al XVII: la redención de cautivos y la dotación de doncellas para el matrimonio". En: CAMPOS Y FERNÁNDEZ DE SEVILLA, Francisco Javier - Religiosidad Popular en España. Actas del Simposium (I). San Lorenzo del Escorial: Real Centro Universitario Escorial, 1997, pp. 163-191. ISBN: 84-89942-00-5.

${ }^{136}$ PÉREZ GONZÁLEZ, Silvia María - La mujer en la Sevilla de finales de la Edad Media. Solteras, casadas y vírgenes consagradas. Sevilla: Universidad, 2005, pp. 54-65. ISBN: 84-472-0878-8; IDEM "De la tipificación a la realidad documentada: las jerezanas a fines de la Edad Media (1392-1505)". En: MIURA ANDRADES, José María y PÉREZ GONZÁLEZ, Silvia María (Dirs.) - Religiosidad sevillana. Homenaje el profesor José Sánchez Herrero. Sevilla: Aconcagua, 2012, pp. 421-452. ISBN: 978-8496178-67-0.
} 
(no está desposada previamente, es huérfana y cristiana vieja), se procede a la dotación, para lo cual se le da el ajuar y se la acompaña el día de la boda ${ }^{137}$. Los ajuares han de ser llevados a la iglesia mayor de la localidad y estar expuestos allí el Jueves Santo ${ }^{138}$ o el Jueves y el Viernes Santo ${ }^{139}$. En otras ocasiones, la cofradía solo aporta el ajuar si la doncella es muy pobre; si no, se le ayuda con alguna alhaja ${ }^{140}$. En última instancia, las cofradías ayudan también a los hijos e hijas de los cofrades que se casan, prestándoles la caldera el día de la boda ${ }^{141}$.

La redención de cautivos en tierras del Islam era también una misión importante en el seno de las cofradías. No olvidemos el carácter de tierra de frontera de la región andaluza durante los últimos siglos de la Edad Media, en una lucha constante entre ambos bandos: los cristianos y los musulmanes. Si algún cofrade, clérigo o lego, caía en manos de estos últimos, la cofradía acudía a su rescate y le ayudaba económicamente en todo lo que hiciera falta ${ }^{142}$.

Por último, las cofradías se ocupaban también de la atención a los presos, a los que se les aplicaban las intenciones de diversos oficios ${ }^{143}$ o se les acompañaba en el caso de que hubieran de perecer en manos de la Justicia, pidiendo limosna para la celebración de sufragios por su alma ${ }^{144}$.

\subsection{Oraciones y celebraciones varias}

Por último, señalaremos algunas oraciones y celebraciones llevadas a cabo por las cofradías para rogar a Dios por diversas causas. En algunas de ellas se celebraban misas diarias con diversas intenciones: por el rey, por las cofradías, por los vivos y difuntos, y

\footnotetext{
${ }^{137}$ IV, 7; CVIII, 7.

${ }^{138}$ CVIII, 8

${ }^{139} \mathrm{IV}, 8$.

${ }^{140}$ XXXVII, 12; CXVII, 17.

${ }^{141}$ LXXXII, 14.

${ }^{142}$ I, 2; LXXXII, 13; LXXXV, 5.

${ }^{143}$ LXXXV, 28.

${ }^{144}$ CVIII, 45 .
} 
por los bienhechores ${ }^{145}$. En otras, se realizaban diversas plegarias el día de la fiesta mayor: por el rey, por el obispo, por los cofrades vivos, por el prior, por determinadas personas y sus familias, por los cofrades difuntos y por las Ánimas del Purgatorio ${ }^{146}$. A veces el prioste de la cofradía era el encargado de rezar todas las noches por vivos y difuntos ${ }^{147}$. Por último, las corporaciones estaban obligadas a celebrar diversas remembranzas por las personas que les habían legado bienes ${ }^{148}$. El muñidor (persona que se encargaba de avisar al resto de cofrades) debía llamar a los hermanos para estas celebraciones desde tres días antes, y se traía juncia o romero, en función de la disponibilidad $^{149}$.

\section{CONCLUSIONES}

La actividad asistencial de las cofradías andaluzas en la Baja Edad Media constituyó sin duda uno de los pilares fundamentales que justificaron su aparición y han motivado su pervivencia hasta nuestros días. Conscientes de la imperiosa necesidad de ejercer la caridad con el prójimo de acuerdo con los mandatos evangélicos, los cofrades andaluces se apresuraron en canalizar su labor benéfica a través de las instituciones más puramente laicales que han existido y existen en el seno de la Iglesia. Esta ayuda no se limitaba únicamente a los propios miembros de las corporaciones, sino que desplegaba un amplio abanico de posibilidades para atender también a cualquier persona necesitada dentro del entorno de las cofradías: desde la ayuda puramente material a la asistencia en la enfermedad y, sobre todo, el acompañamiento durante el paso a la otra vida. Podemos afirmar sin ningún tipo de dudas que fue este el campo de acción más privilegiado, por encima de la asistencia material ante la pobreza y otras obras de caridad a las que ya nos hemos referido. Las corporaciones se ocupaban de atender a sus propios cofrades en tan duro trance, pero no solo a ellos, sino también a toda su familia: las esposas, siempre en un puesto preferente y con la misma categoría que los propios cofrades, y después todo

$145 \mathrm{I}, 5$

${ }^{146}$ LXXXV, 10.

${ }^{147} \mathrm{XCV}, 9$.

${ }^{148}$ CVIII, 41; CIX, 3; IV, 35.

${ }^{149}$ XXXVII, 43. 
el rango de familiares: hijos, padres, suegros e incluso personas a su servicio, como esclavos y mozos. Podemos interpretar esta supremacía de las honras fúnebres dentro de la acción social de las cofradías como un reflejo de la realidad vivida en la época de la que nos estamos ocupando: la muerte era una compañera habitual en las vidas -valga la redundancia- de las personas. Habían de convivir necesariamente con ella, pues la esperanza de vida no era realmente muy elevada, debido a la profusión de diversas enfermedades y a la insalubridad presente en las ciudades. Y, siendo realistas, es lógico pensar que este campo fuera el predilecto de las corporaciones, pues aunque muchas no descuidaran la asistencia al gran número de pobres que las rodeaban, lo más probable era que la muerte llamara pronto a la puerta de cualquier persona cuyas condiciones de vida no fueran mínimamente dignas. El entierro de los muertos era igualmente una de las obras de misericordia corporales, y rogar por ellos otra obra de misericordia espiritual, por lo que es fácil atisbar que, en la práctica de estas acciones virtuosas, los cofrades se decantaran por las que sin duda eran las más necesarias habida cuenta de la realidad social en que vivían. No obstante, ya hemos destacado que también practicaban otras, preferentemente: dar de comer a los hambrientos y visitar a enfermos y encarcelados, entre las corporales; consolar al que lo necesita, sobre todo en la enfermedad, y perdonar al que yerra, entre las espirituales. Todo ello sin menoscabo de todas las prácticas que no quedan recogidas en la documentación por nosotros estudiada.

En definitiva, creemos haber aportado un buen botón de muestra que nos ilustra cómo vivía la sociedad andaluza bajomedieval el mandato de amor y caridad predicado por Jesús de Nazaret muchos siglos antes.

Data recepção do artigo: 18 de Abril de 2012

Data aceitação do artigo: 10 de Abril de 2013 


\section{FUENTES ESCRITAS}

Como se ha indicado a lo largo del trabajo, el sustento documental del presente artículo se ha basado en un corpus de reglas de hermandades y cofradías andaluzas de los siglos XIV, XV y XVI recopiladas en:

SÁNCHEZ HERRERO, José (Dir.) y PÉREZ GONZÁLEZ, Silvia Ma (Coord.) - CXIX Reglas de Hermandades y Cofradías andaluzas. Siglos XIV, XV y XVI. Huelva: Universidad de Huelva, 2002. ISBN: 84-95699-34-6.

A lo largo del trabajo ya hemos hecho referencia a las reglas concretas utilizadas. No volvemos a repetirlas aquí por cuestiones espaciales.

\section{REFERENCIAS BIBLIOGRÁFICAS COMPLETAS}

ARBOLEDA GOLDARACENA, Juan Carlos - "Contrarreforma y religiosidad popular en Andalucía: cofradías y devoción mariana". En: Tiempos modernos: revista electrónica de Historia Moderna, vol. 7, n²0, (2010). ISSN: 1699-7778.

ARBOLEDA GOLDARACENA, Juan Carlos - "El gobierno de las hermandades y cofradías andaluzas en la Baja Edad Media". En: VV.AA. (Eds.) - Mundos medievales: espacios, sociedades y poder. Homenaje al Profesor José Ángel García de Cortázar. Santander: Universidad de Cantabria-Fundación Marcelino Botín-Instituto de Estudios Riojanos, 2012, vol. 2, pp. 1005-1014. ISBN: 978-84-8102-649-8.

CARMONA GARCÍA, Juan Ignacio - El sistema de la hospitalidad pública en la Sevilla del Antiguo Régimen. Sevilla: Diputación Provincial, 1979. ISBN: 84-500-3472-8.

CARMONA GARCÍA, Juan Ignacio - El extenso mundo de la pobreza: la otra cara de la Sevilla imperial. Sevilla: Ayto. de Sevilla, 1993. ISBN 84-86810-30-2. 
CARMONA GARCÍA, Juan Ignacio - Las redes asistenciales en la Sevilla del Renacimiento. Sevilla: Universidad, 2009. ISBN: 978-84-472-1180-7.

DÍEZ DE VELASCO, Francisco - Teorías y metodologías para el estudio de las religiones. Recurso online. Disponible en:

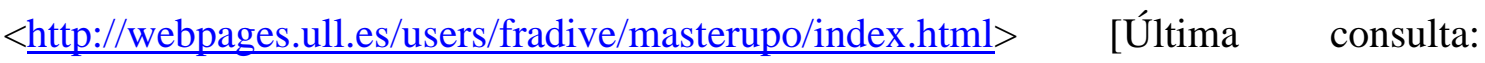
$19 / 2 / 2012]$

GEMEREK, Bronislaw - "L'emarginato". En LE GOFF, Jacques (Ed.) - L'uomo medievale. Roma: Laterza, 1987, pp. 391-421. ISBN: 978-88-420-4197-9.

LABOA GALLEGO, Juan $\mathrm{M}^{\mathrm{a}}$ - Los laicos en la Iglesia. Madrid: BAC, 2003. ISBN: 84-7914-662-1.

LABOA GALLEGO, Juan $\mathrm{M}^{\mathrm{a}}$ - Por sus frutos los conoceréis. Historia de la caridad en la Iglesia. Madrid: San Pablo, 2011. ISBN: 978-84-285-3887-9.

LÓPEZ GUTIÉRREZ, Antonio J. y RODRÍGUEZ MATEOS, Joaquín - Los archivos de las hermandades religiosas. Manual de organización de fondos. Sevilla: G.E.A., 1993. ISBN 84-604-5659-5.

LÓPEZ GUTIÉRREZ, Antonio J. y RODRÍGUEZ MATEOS, Joaquín - Archivos y documentos en las hermandades sevillanas. Sevilla: Castillejo, 2000. ISBN: 84-8058137-9.

MUÑOZ FERNÁNDEZ, Ángela - "Las mujeres en los ámbitos institucionales de la religiosidad laica: las cofradías devocionales castellanas". En: MUÑOZ FERNÁNDEZ, Ángela y GRAÑA CID, $\mathrm{M}^{\mathrm{a}}$ del Mar - Religiosidad femenina: expectativas y realidades (ss. VIII-XVIII). Madrid: Al-Mudayna, 1991, pp. 93-114. ISBN: 84-87090-05-2.

PÉREZ GONZÁLEZ, Silvia Maria - Los laicos en la Sevilla bajomedieval: sus devociones y cofradías. Huelva: Universidad, 2005. ISBN: 84-96373-61-4.

PÉREZ GONZÁLEZ, Silvia María - La mujer en la Sevilla de finales de la Edad Media. Solteras, casadas y vírgenes consagradas. Sevilla: Universidad, 2005. ISBN: 84-472-0878-8. 
PÉREZ GONZÁLEZ, Silvia Maria - "Aspectos socio-caritativos de las Cofradías de la Cruz andaluzas (siglos XV y XVI)". En: Actas del IV Congreso Internacional de Hermandades y Cofradías de la Vera Cruz. Zamora, 2008, pp. 717-738. ISBN: 8496100-38-3.

PÉREZ GONZÁLEZ, Silvia María - "De la tipificación a la realidad documentada: las jerezanas a fines de la Edad Media (1392-1505)". En: MIURA ANDRADES, José María y PÉREZ GONZÁLEZ, Silvia María (Dirs.) - Religiosidad sevillana. Homenaje el profesor José Sánchez Herrero. Sevilla: Aconcagua, 2012, pp. 421-452. ISBN: 97884-96178-67-0.

SÁNCHEZ DOMÍNGUEZ, Paloma - Mujeres y cofradías en Málaga. Málaga: Arguval, 2003. ISBN: 84-95948-34-6.

SÁNCHEZ HERRERO, José - Las diócesis del reino de León. Siglos XIV y XV. León: Centro de Estudios e Investigación "San Isidoro", 1978. ISBN: 84-00-03796-0.

SÁNCHEZ HERRERO, José - "Las cofradías sevillanas. Los comienzos". En: SÁNCHEZ HERRERO, José et al. (eds.) - Las cofradías de Sevilla: historia, antropología, arte. Sevilla: Universidad, 1985, pp. 9-34. ISBN: 84-472-0511-8.

SÁNCHEZ HERRERO, José - "Las cofradías de Semana Santa de Sevilla durante la modernidad. Siglos XV a XVII". En: SÁNCHEZ MANTERO, Rafael et al. (eds.) - Las cofradías de Sevilla en la modernidad. Sevilla: Universidad, 1988, pp. 27-88. ISBN: 84472-0509-6.

SÁNCHEZ HERRERO, José - "Los años refundacionales del Cristianismo en la ciudad y diócesis de Sevilla, 1248-1286". En: ROS, Carlos (Dir.) - Historia de la Iglesia de Sevilla. Sevilla: Castillejo, 1992, pp. 103-166. ISBN: 84-8058-005-4.

SÁNCHEZ HERRERO, José - "El origen de las cofradías penitenciales". En: VV.AA. (Eds.) - Sevilla Penitente. Sevilla: Gever, 1995, tomo I, pp. 13-55. ISBN: 84-88566-32-8. 
SÁNCHEZ HERRERO, José - "El origen de las cofradías de Semana Santa o de Pasión en la Península Ibérica". En: Temas Medievales. Buenos Aires. N 6, (1996), pp. 31-79. ISSN: 0327-5094.

SÁNCHEZ HERRERO, José - "La acción benéfica de las cofradías durante los siglos XIV al XVII: la redención de cautivos y la dotación de doncellas para el matrimonio". En: CAMPOS Y FERNÁNDEZ DE SEVILLA, Francisco Javier - Religiosidad Popular en España. Actas del Simposium (I). San Lorenzo del Escorial: Real Centro Universitario Escorial, 1997, pp. 163-191. ISBN: 84-89942-00-5.

SÁNCHEZ HERRERO, José - "Piedad y artes plásticas. La devoción a la Preciosa Sangre de Cristo durante los siglos XIII a los primeros años del XVI y su influencia en las manifestaciones artísticas". En: Actas do Colóquio Internacional: Piedade popular. Sociabilidades-Representações-Espiritualidades. Lisboa: Terramar, 1999, pp. 411-432. ISBN: 972-710-253-0.

SÁNCHEZ HERRERO, José - La Semana Santa de Sevilla. Madrid: Sílex, 2003. ISBN: 978-84-7737-120-5.

SÁNCHEZ HERRERO, José - "Apuntes para un manual de Historia de la Iglesia medieval, siglos V al XV". En: Historia, Instituciones, Documentos. No 31, (2004), pp. 645-658. ISSN: 0210-7716.

SÁNCHEZ HERRERO, José - "La evolución de las hermandades y cofradías desde sus momentos fundacionales hasta nuestros días". En: Consejo General de Hermandades y Cofradías de la Ciudad de Sevilla. Recurso online. Disponible en: 〈http://www.hermandades-de-sevilla.org/hermandades/historiahermandades.htm> [Última consulta: 19/2/2012].

SÁNCHEZ HERRERO, José y PÉREZ GONZÁLEZ, Silvia Maria - "La Cofradía de la Preciosa Sangre de Cristo de Sevilla. La importancia de la devoción a la Preciosa Sangre de Cristo en el desarrollo de la devoción y la imaginería de la Semana Santa". En: Aragón en la Edad Media. Homenaje a la profesora Carmen Orcástegui Gros. Zaragoza. No XIV-XV, (1999), pp. 1429-1452. ISSN: 0213-2486. 
SÁNCHEZ HERRERO, José (Dir.) y PÉREZ GONZÁLEZ, Silvia Maria (Coord.) CXIX Reglas de Hermandades y Cofradías andaluzas. Siglos XIV, XV y XVI. Huelva: Universidad de Huelva, 2002. ISBN: 84-95699-34-6.

The Confraternities Collection. Recurso en línea. Disponible en: <http://www.crrs.ca/Confraternitas/collect.htm> [Última consulta: 20/3/2013].

\section{COMO CITAR ESTE ARTIGO}

\section{Referência electrónica:}

ARBOLEDA GOLDARACENA, Juan Carlos - "La caridad en la historia del cristianismo: algunas manifestaciones en la Andalucia bajomedieval". Medievalista [Em linha]. N¹4, (Julho - Dezembro 2013). [Consultado dd.mm.aaaa]. Disponível em http://www2.fcsh.unl.pt/iem/medievalista/MEDIEVALISTA14/goldaracena1403.html.

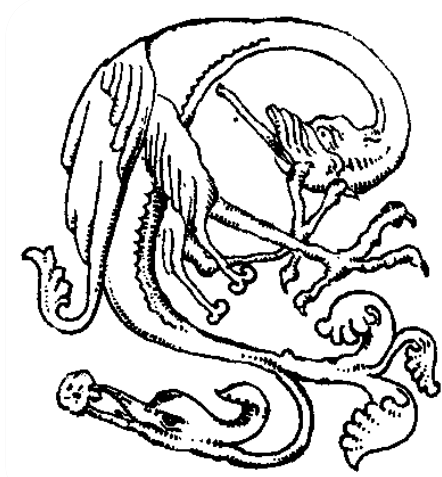

